\title{
Characterising and modelling the mechanical behaviour of polymeric foams under complex loading
}

\author{
I. Carranza ${ }^{1,2, *}$ (1) A. D. Crocombe ${ }^{1}$ (D), I. Mohagheghian ${ }^{1}$ (D), P. A. Smith ${ }^{1}$ (I), \\ A. Sordon ${ }^{2}$ (I) , G. Meeks ${ }^{2}$ (I), and C. Santoni ${ }^{2}$ \\ ${ }^{7}$ Mechanical Engineering Sciences, University of Surrey, Guildford GU2 7XH, UK \\ ${ }^{2}$ McLaren Automotive Ltd, Woking GU21 4YH, UK
}

Received: 29 January 2019

Accepted: 29 April 2019

Published online:

10 May 2019

(C) The Author(s) 2019

\begin{abstract}
Polymeric foams are used extensively as the core of sandwich structures in automotive and aerospace industries. Normally, several experiments are necessary to obtain the required properties to model the response of crushable foams using finite element analysis (FEA). Hence, this research aims to develop a simple and reliable calibration process for extracting the physical parameters which are required by the material model available in the commercial FE package Abaqus. To do this, a set of experimental tests, including uniaxial compression, uniaxial tension and shear punch tests, is proposed. All the experimental tests were also simulated, and generally, good correlations between experiments and numerical models were obtained. The validity of the overall approach was finally demonstrated using an indentation test in which the foam was subjected to a more complex mixed mode loading. During these indentation tests, digital image correlation was used to observe full-field strain distribution in the foam under the indenter. Good agreement between the experimental results and the numerical predictions was found for load-displacement response, failure mode and strain distribution.
\end{abstract}

\section{Introduction}

To improve the efficiency of vehicles, reducing the weight of structures has become a major target in automotive and aerospace industries. To achieve this goal, several classes of materials have emerged in the last decade as alternatives to more traditional construction materials. Sandwich panels with skins made of fibre reinforced composites and core made of a lightweight material are now used widely in the aerospace sector. The application of composite sandwich structures in the automotive industry is also growing because of the advantages of these structures, such as high stiffness to weight ratio and high energy absorption capabilities.

Selection of a suitable core material for a sandwich structure is a crucial part of the design process to have components which are lightweight and have adequate impact (crash) resistance. There are several materials which have been used for the core of

Address correspondence to E-mail: i.carranza-guisado@surrey.ac.uk 
sandwich structures, including aluminium or polymeric foams, aluminium lattice, honeycombs, balsa and cork. Nowadays, transportation industries are particularly interested in the use of polymeric foams as the core of crushable devices, due to the wide variety of synthetic polymers (available in various densities) and their capability for absorbing large amounts of energy, especially when loaded in compression. Due to their complex microstructure, the mechanical response of foams depends on several structural factors including density, cell size, wall thickness and cell geometry [1-3], as well as loading conditions. To model the response of crushable foams, several mechanical properties need to be extracted from experimental tests for calibrating the material models which are available in commercial Finite Element (FE) packages.

Various material models are available to analyse foams, with "Crushable Foam" being the most commonly used one in the commercial FE package Abaqus. This material model is based on the constitutive equations developed by Deshpande and Fleck [4]. In their study, Deshpande and Fleck [4] investigated the evolution of the yield surface of two metallic foams under uniaxial and hydrostatic compression loading. A number of proportional axisymmetric stress paths were studied using a triaxial cell. Then, by varying the applied pressure, authors were able to extract a number of points in the mean stress-von Mises effective stress space. They concluded that the yield surface was of quadratic shape and it evolved without corner formation (i.e. elliptical shape). It should be noted that only the stress-strain data obtained from uniaxial and hydrostatic compression tests were used to calibrate the model. To validate their work, Deshpande and Fleck used their constitutive model to predict the yield strength of the foams under tensile and shear loading (i.e. loading conditions different from those of calibration). Their results suggested a good agreement between the predicted strengths and the experimental values from previous work on the same metallic foams by Harte et al. [5].

Deshpande and Fleck also studied the applicability of their constitutive model for two specific PVC foams [6]. Materials were tested under different loading conditions, including: hydrostatic compression, hydrostatic tension, uniaxial compression, uniaxial tension and pure shear. Two multi-axial loading systems were used to investigate the response of the foams under different combinations of tension and compression. In addition, the shear behaviour was studied using the "Arcan" test. They found that the assumptions which were made for the metallic foams (i.e. similar strengths in uniaxial compression, uniaxial tension, hydrostatic compression and pure shear) did not apply for the PVC foams. The yield strengths of the material were not similar in different loading conditions. These results highlight that material characterisation is essential in order to be able to calibrate numerical models for each particular foam system. It should also be mentioned that Deshpande and Fleck [6] defined "yield" strength in tension and shear of their foam materials as the intersection of the extrapolation of the linear and nonlinear regions in the stress-strain curve. This defined concept of "yielding" in polymeric foams does not have the same micromechanics of deformation as, for example, metal yielding has. The deviation from the elastic trend can be a combination of accumulative damage and/or some local plastic deformation within the cell walls before the final fracture in a brittle manner $[1,7]$. However, it is very challenging to model these detailed mechanisms and, therefore, a phenomenological rather than mechanistic approach has been adopted for the determination of yield strengths as previously employed by Deshpande and Fleck [6].

As already mentioned, the "Crushable Foam" model which is considered in this investigation uses the expressions from the constitutive model developed by Deshpande and Fleck [4] to create the yield surface of the material, as illustrated in Fig. 1. The surface is defined by Eqs. (1)-(4) [8], and they require the definition of physical parameters in order to predict the response of the material. In particular, three main inputs are needed for defining the yield envelope in the hydrostatic pressure $(p)$-von Mises stress $(q)$ space, including hydrostatic compressive strength $\left(p_{c}\right)$, hydrostatic tensile strength $\left(p_{t}\right)$ and uniaxial compressive yield strength $\left(\sigma_{c}\right)$. In Abaqus, $p_{c}$ and $p_{t}$ are introduced as the ratios of uniaxial compressive yield strength to hydrostatic compressive strength $(K)$ and hydrostatic tensile strength to hydrostatic compressive strength $\left(K_{t}\right)$, respectively. The stress-strain curve under uniaxial compressive loading is also needed to define the densification process of the foam and hence the hardening (introduced in the model as $\alpha$ and represented as a line in Fig. 1). If necessary, the material model allows the definition of strain rate dependency, which shifts the 


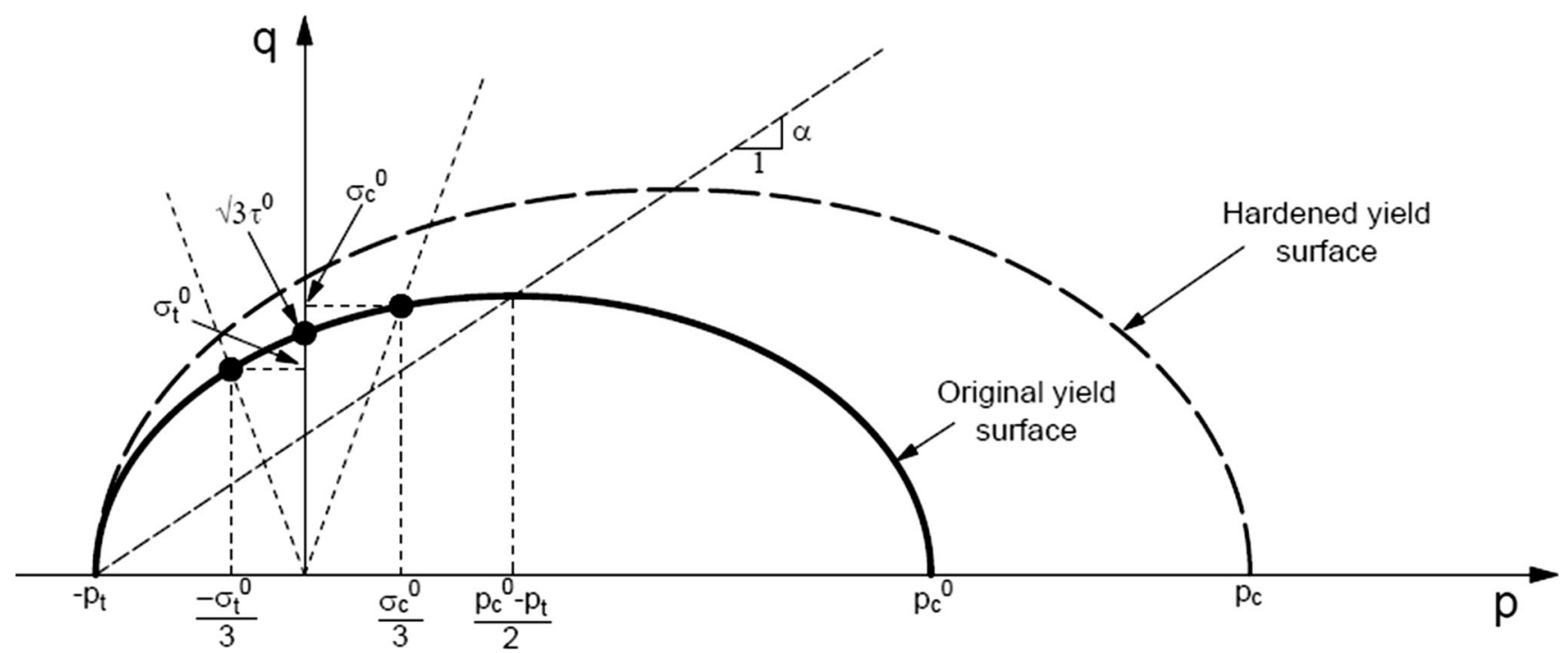

Figure 1 Yield surface of the "Crushable Foam" material model, including the points which are used in the proposed calibration process. $\sigma_{t}$ is the uniaxial tensile yield strength; $\sigma_{c}$ is the uniaxial

uniaxial compressive stress-strain curve in the numerical model. Note that the definition of the previously mentioned parameters as inputs would recreate the yield surface using three points well separated in the $p-q$ space, which would be desirable. Nevertheless, the extraction of hydrostatic strengths requires complex testing set-ups, complicating the calibration process of the material model.

$\frac{\left(p-\frac{p_{c}-p_{t}}{2}\right)^{2}}{\left(\frac{p_{c}+p_{t}}{2}\right)^{2}}+\frac{q^{2}}{\left(\alpha \frac{p_{c}+p_{t}}{2}\right)^{2}}=1$

$K=\frac{\sigma_{c}}{p_{c}}$

$K_{t}=\frac{p_{t}}{p_{c}}$

$\alpha=\frac{3 K}{\sqrt{\left(3 K_{t}+K\right)(3-K)}}$

Extracting the material parameters from experimental results is then another challenge, as no standard process has been established for crushable foams. In general, the compressive behaviour is well established and it can be tested easily [1, 9-18]. However, a simple and reliable methodology for extracting the main features of the tensile and shear responses (i.e. tensile and shear moduli, yielding points, ultimate strengths or failure strains) has yet to be achieved. Although there are now a number of studies which have considered the characterisation of compressive yield strength; $\tau$ is the shear strength; notation " 0 " refers to the original yield surface (prior to suffer hardening).

crushable foams under tensile and shear conditions $[5,6,9,16,18-22]$, there is not yet any standard experimental procedures for extracting the strengths of the material. For instance, with regards to the tensile response of polymeric foams, dog bone specimens are often used, although the geometry of the samples varies depending on the publication. Some researchers $[5,6,16,18,19,22]$ did not mention any standard on which their specimens were based, whereas other authors $[9,20]$ conducted their tensile tests according to ASTM C297 [23], which does not even consider dog bone specimens. In addition to the different options which have been reported to study the tensile behaviour of foams, several experimental procedures were found in the literature to study the shear response. For example, $[4,6]$ referred to private communication when they presented results for double-lap shear tests; in [6, 22], the shear properties of the foams were extracted by conducting Arcan tests; other authors performed single-lap shear tests $[9,20,21]$ according to ASTM C273 [24]; elsewhere, [16] single-lap shear tests were conducted on prismatic specimens with an I-shaped cross section (with shear deformation occurring only in the web of the I-beam); finally, some authors [19] designed a custom fixture in order to study the shear behaviour, as they were concerned about friction effects from the test proposed in ASTM C273 [24].

Since it was found that there were many possibilities regarding the experimental tests which could be 
conducted to characterise this type of material, this paper aims to propose a systematic process for calibrating the "Crushable Foam" material model available in Abaqus. The approach which is proposed in this study was developed by characterising two different polymeric foams under three well-defined stress states: uniaxial compression, tension and shear. Hence, this methodology aims to provide an alternative to the more challenging hydrostatic tests. Finally, the validity of the calibration process was checked under mixed loading conditions using an indentation test. Digital image correlation (DIC) was employed during the indentation test to monitor the strain distribution under this multi-axial loading condition. The test was then simulated using FEA, and the numerical predictions were correlated with the experimental results.

\section{Materials and methods}

\section{Materials}

Two closed cell rigid cellular foams with the same parent polymer but with different characteristics (i.e. different density, cell size and manufacturing process) were considered in this study. These two foams will be referred as foam A and foam B, respectively. The density of foam A was about $30 \%$ lower than density of foam B, with relative densities of around $6 \%$ and $9 \%$, respectively $[6,9,25]$. A comparison between the cell sizes is illustrated in the photomicrographs shown in Fig. 2, obtained by Bragagnolo (private communication, 2018) using scanning electron microscopy (SEM). It was determined that the characteristic cell size was $400 \mu \mathrm{m}$ and $50 \mu \mathrm{m}$ for foams A and B, respectively. Regarding the manufacturing process, foam A was created following the traditional foaming process. After manufacturing the material in bulk, the foam was machined to the desired shape and geometry. On the other hand, foam B was manufactured by placing polymer pellets in a mould which then expanded and created the final material with the shape of the mould.

\section{Calibration methodology}

The yield surface of the "Crushable Foam" material model can be recreated following Eqs. (1)-(4) [8], which were introduced in "Introduction" section. As
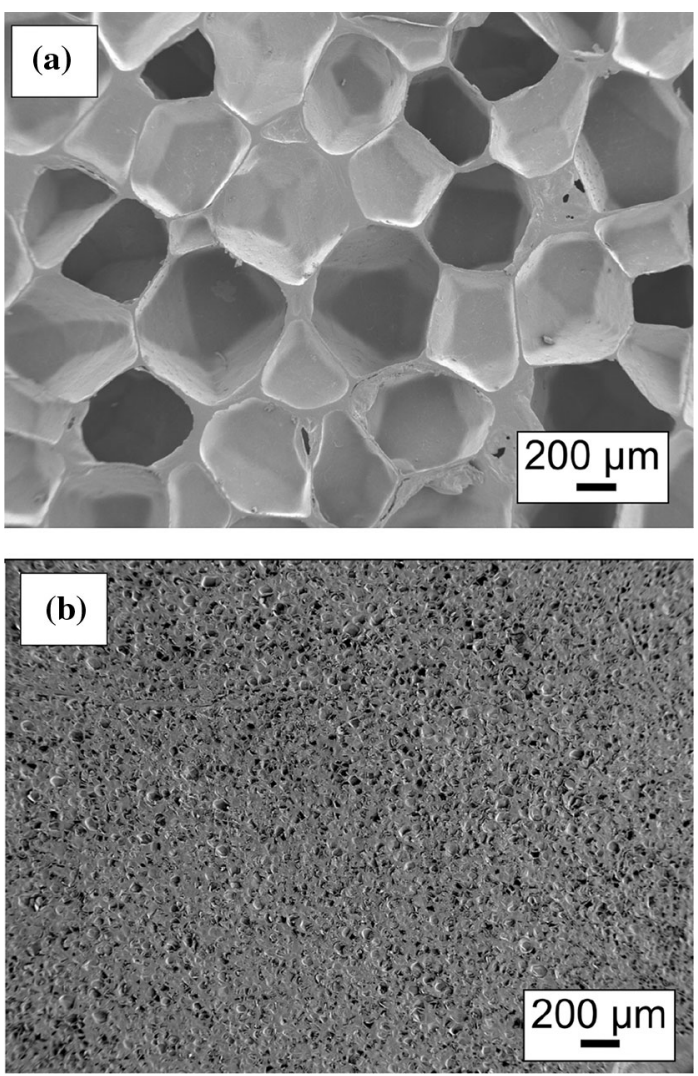

Figure 2 Comparison between the microstructure of: a foam A and $\mathbf{b}$ foam $\mathbf{B}$. Images were taken using SEM.

discussed before, using hydrostatic compressive strength, hydrostatic tensile strength and uniaxial compressive yield strength as the main inputs for calibrating, the model is beneficial, as these points are well separated in the $p-q$ space. However, obtaining those parameters requires a very complex test set-up, including tests in a pressurised environment. Alternatively, the yield surface can also be calibrated using three other points in the $p-q$ space, including uniaxial tension $\left(p=-\sigma_{t} / 3, q=\sigma_{t}\right)$, uniaxial compression $\left(p=\sigma_{c} / 3, q=\sigma_{c}\right)$ and pure shear $(p=0, q=\sqrt{3} \tau)$, where $\sigma_{t}, \sigma_{c}$ and $\tau$ represent uniaxial tensile strength, uniaxial compressive yield strength and shear yield strength of the foam, respectively. Although these points are much closer together in the $p-q$ space, we believe that they are sufficiently separated to recreate the yield surface in a relatively accurate manner. Obtaining these values, however, requires much simpler experimental arrangements. The shape of the yield surface as well as the location of these three points is introduced in Fig. 1. 
It should be noted that because of the difficulty of obtaining hydrostatic compressive and tensile strength values, many researchers $[4,6,9,15]$ assume constant ratios of the uniaxial compressive yield strength to hydrostatic compressive strength $(K)$ and the hydrostatic tensile strength to hydrostatic compressive strength $\left(K_{t}\right)$, based on the experiments which were conducted on other foams. The accuracy of the calibration process which is proposed in this study will be assessed later using a more complex multi-axial loading case, and the predictions of the numerical model will be compared to experimental results in "Validation of the calibration process through an indentation test" section.

\section{Experimental tests}

Uniaxial compression tests were conducted following ASTM C365/C365 M-16 [26] and undertaken at room temperature. Rectangular samples were used for both foams, with a cross-sectional area of $25 \mathrm{~mm} \times 25$ $\mathrm{mm}$. The thickness of foam A was $17 \mathrm{~mm}$, while 15-mm-thick specimens were tested for foam B. Samples were tested using a screw-driven Instron 5500R-1185 machine with a cross-head speed of $0.5 \mathrm{~mm} / \mathrm{min}$, as recommended by the standard. A $100-\mathrm{kN}$ load cell and the cross-head displacement were used to measure the load-displacement curves. According to the standard, at least five repetitions should be carried unless valid results could be obtained using fewer samples. In this case, excellent repeatability was observed and only three specimens were tested for each foam.

Uniaxial tensile tests were based on BS ISO 1926:2009 [27] and undertaken at room temperature. The geometry of the specimens was slightly modified with respect to the standard to promote failure within the gauge length. Final dimensions are shown in Fig. 3, where $t$ shows the thickness of the specimens: $16 \mathrm{~mm}$ for foam A and $15 \mathrm{~mm}$ in the case of foam B. To fix the samples onto the testing rig, an 8-mm hole was drilled in each grip zone and, in order to avoid the failure of the foam in the hole areas, both ends were reinforced with 2-mm-thick end tabs made of glass fibre (Tufnol). A screw-driven Instron 5500R6025 machine was employed, and tests were conducted with a cross-head speed of $1 \mathrm{~mm} / \mathrm{min}$. The load-displacement curves were recorded using the cross-head displacement and a 100-kN load cell. Five specimens were tested for each foam, following the standard recommendations.

Shear punch tests were performed according to ASTM D732-17 [28] at room temperature. A schematic of the sample geometry and the cross section of the set-up is illustrated in Fig. 4. Samples consisted of blocks with a square cross-sectional area of $50 \mathrm{~mm} \times 50 \mathrm{~mm}$ and a thickness of $3 \mathrm{~mm}$. The punch diameter was $19.90 \mathrm{~mm}$, and it was pushed through a $20-\mathrm{mm}$ hole using a screw-driven AG-X Shimadzu machine with a cross-head speed of $1.25 \mathrm{~mm} / \mathrm{min}$. The load-displacement response was measured using a $100-\mathrm{kN}$ load cell and the crosshead displacement. Following the standard, five specimens were tested to check the repeatability of the results.

It should be mentioned that despite similarity in cross-head speed, the nominal strain rate that material experienced was different for various loading conditions. For both foams $\mathrm{A}$ and $\mathrm{B}$, the nominal strain rate was $0.0005 \mathrm{~s}^{-1}, 0.0003 \mathrm{~s}^{-1}$ and $0.007 \mathrm{~s}^{-1}$ for uniaxial compression, uniaxial tension and shear, respectively. In a separate test, not reported in this paper, we examine the strain rate sensitivity of both foams under uniaxial compression for strain rates ranged between $0.0005 \mathrm{~s}^{-1}$ and $0.005 \mathrm{~s}^{-1}$. For the range considered, it was found out that strain rate only has a modest effect on yield strength (i.e. an increase in strain rate by an order of magnitude only caused 7\% increase in yield strength). Therefore, we believe that that it is reasonable to use these data, although slightly in different strain rates, as input for our calibration process in quasi-static loading.

A schematic of the indentation test is included in Fig. 5, including dimensions. The test consisted of a $140 \mathrm{~mm} \times 140 \mathrm{~mm}$ block of foam (different thickness depending on the foam) fixed at the bottom with a screw clamp and loaded by displacing a cylindrical steel indenter at $1 \mathrm{~mm} / \mathrm{min}$. A screw-driven Instron 5982 machine was used, and 3D-DIC was employed using a set of two synchronised Manta G-917B ASG cameras. The speckle was spray painted on the surface of the foam which was facing the cameras. An initial layer of white paint was applied to the surface on which black speckles (to create contrast) were sprayed in a non-repetitive pattern. The average speckle size was $0.32 \mathrm{~mm}$ for foam A and $0.03 \mathrm{~mm}$ for foam B, and they are illustrated in Fig. 6 . Although both speckles were created following the same process, it was found that the large number of 


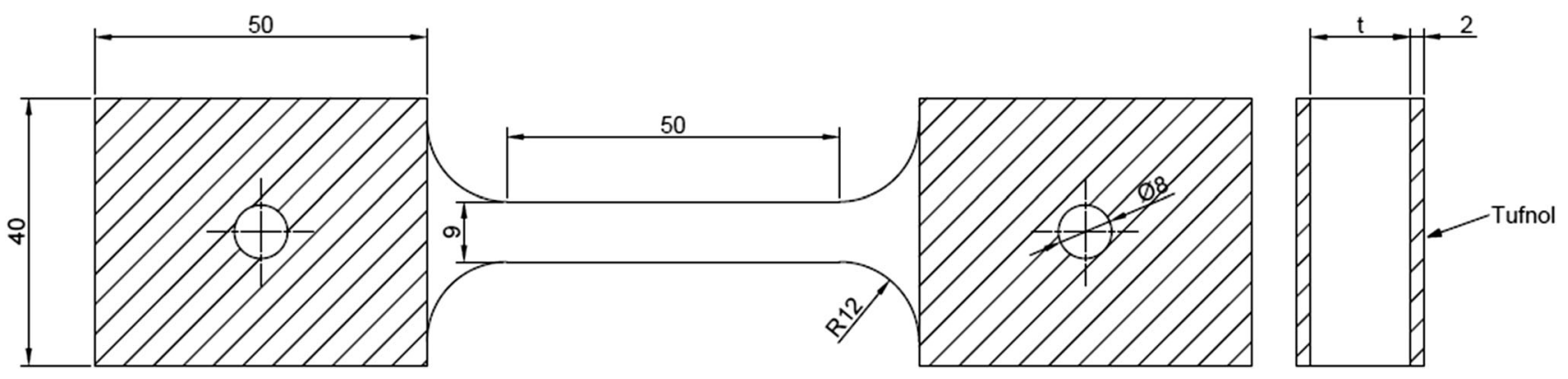

Figure 3 Dimensions of the samples for uniaxial tensile tests (in $\mathrm{mm}$ ), where $t$ is $16 \mathrm{~mm}$ for foam A and $15 \mathrm{~mm}$ for foam B.

Figure 4 Schematic of the shear punch test: a dimensions of the foam specimens (in $\mathrm{mm}) ; \mathbf{b}$ cross section of the test set-up. (a)

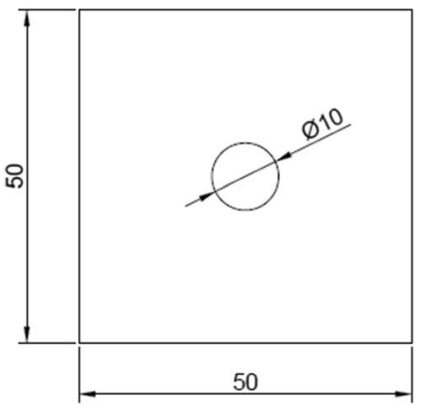

(b)
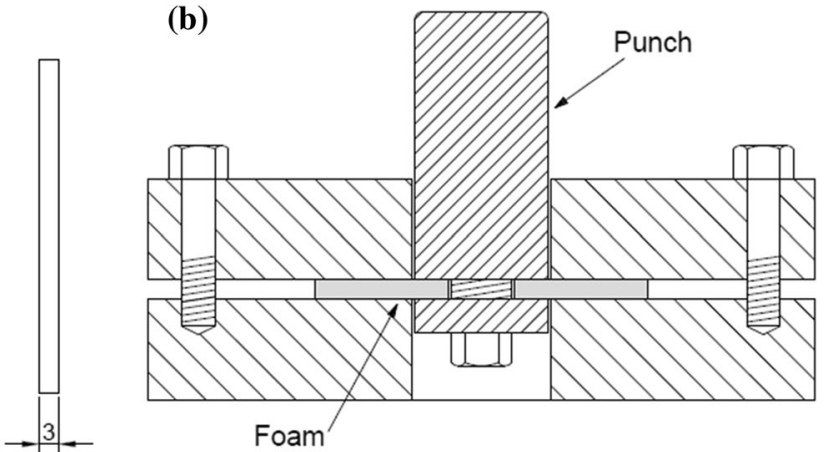

Figure 5 Schematic of the mixed mode indentation test, including a table with the dimensions of the set-up.

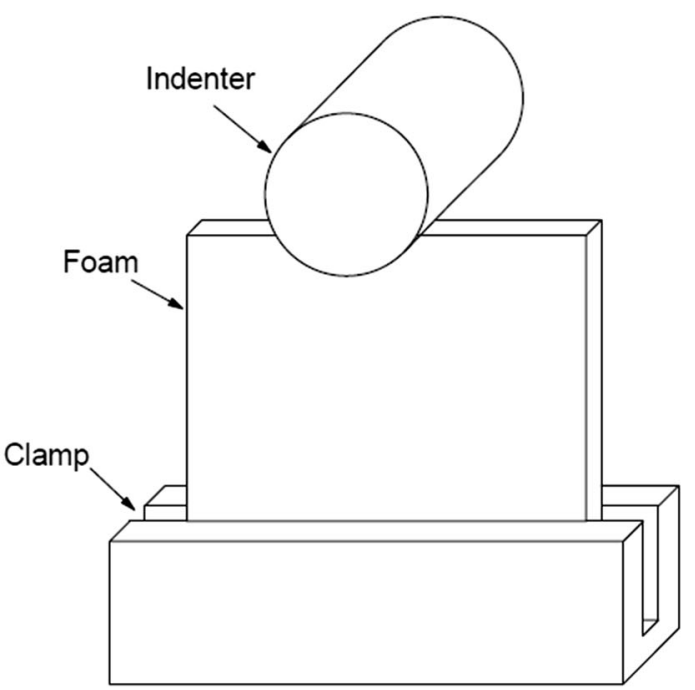

\begin{tabular}{|c|c|}
\hline \multicolumn{2}{|c|}{ Dimensions (mm) } \\
\hline Indenter diameter & 57 \\
\hline Indenter length & 97 \\
\hline Thickness (foam A) & 16 \\
\hline Thickness (foam B) & 15 \\
\hline Foam height & 140 \\
\hline Foam width & 140 \\
\hline Clamping heigth & 40 \\
\hline
\end{tabular}

imperfections which were present on the surface of foam B (such as voids between grain boundaries) made it more complicated to generate a higher quality speckle. This is observed in Fig. $6 \mathrm{~b}$, where some areas present a less homogeneous speckle pattern than foam A. Two repetitions were conducted for each foam at room temperature, and the loaddisplacement response was measured using a $100-\mathrm{kN}$ load cell and the cross-head displacement.

\section{Finite element modelling}

Numerical simulations were performed with Abaqus/Explicit (Abaqus 2017), using the "Crushable Foam" material model. For all cases, the parts were meshed with hex elements and enhanced hourglass control (C3D8R). Rigid bodies were discretised using R3D4 elements in the shear and indentation tests. An illustration of the FE models for uniaxial tension, shear and indentation tests is presented in Fig. 7. Note that since the strain hardening in the model was 


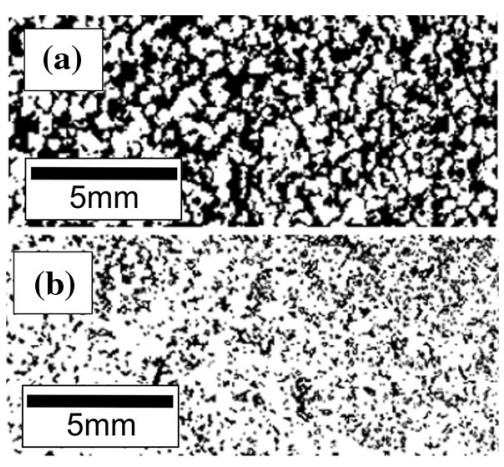

Figure 6 Image of the speckle used to measure the strain fields during the indentation tests using DIC: $\mathbf{a}$ foam A; $\mathbf{b}$ foam B.

calibrated using stress-strain data under uniaxial compression, the simulations under those loading conditions are not included in this paper. With regards to the boundary conditions, the tensile sample was fully constrained on the bottom surface and a constant velocity was applied to the nodes on the top surface; for the shear punch test, the bottom surface of the foam was clamped, except for the area under the indenter, and a constant velocity was applied to the reference point of the punch; for the indentation test, the front and rear surfaces were clamped over the bottom $40 \mathrm{~mm}$ (see Fig. 5), as well as the bottom surface, and a constant velocity was applied to the reference point on the indenter. For the tensile and shear punch tests, the interaction between the rigid bodies and the foam was introduced as a general contact with a friction coefficient of 0.2. Even though the experiments were conducted at quasi-static rates, the velocity which was defined for all models was $2000 \mathrm{~mm} / \mathrm{s}$ in order to reduce computational time.
However, the model only included the material properties from quasi-static tests and the effect of the loading rate was not considered. In addition, to check that this approach was still valid, other two conditions were confirmed: (i) the applied velocity was not greater than $1 \%$ of the speed of sound in the material; (ii) the total kinetic energy did not exceed $10 \%$ of the value of the total internal energy.

Regarding the model of the punch, a fillet of $0.5 \mathrm{~mm}$ radius was introduced around the periphery of the part to avoid stress concentrations in the foam. In addition, for the punch simulation, the foam was meshed so that more elements were located under the punch. A representation of the fillet and the element distribution in one quarter of the foam are shown in Fig. 8. For the tensile and indentation tests, the element size was $1 \mathrm{~mm}$, whereas the minimum element size which was defined for the shear punch test was $0.3 \mathrm{~mm}$. Different meshes were considered to see how sensitive the models were with respect to element size. To do so, each model was meshed with different element sizes, and for each case, the reaction force was extracted at the same displacement. As observed in Fig. 9, results for both tensile and indentation tests became insensitive to the size of the mesh for elements smaller than $4 \mathrm{~mm}$. For the shear punch test, a much finer mesh (i.e. elements smaller than $0.6 \mathrm{~mm}$ ) was necessary to remove this dependency. This was caused by the localised deformation in the area between the punch and the die, as will be explained later in "Calibration of the material model" section. It was also found that defining more elements under the fillet of the punch increased the
Figure 7 Representation of the FE models for: a uniaxial tensile test; $\mathbf{b}$ mid-section of the shear punch test; c indentation test.
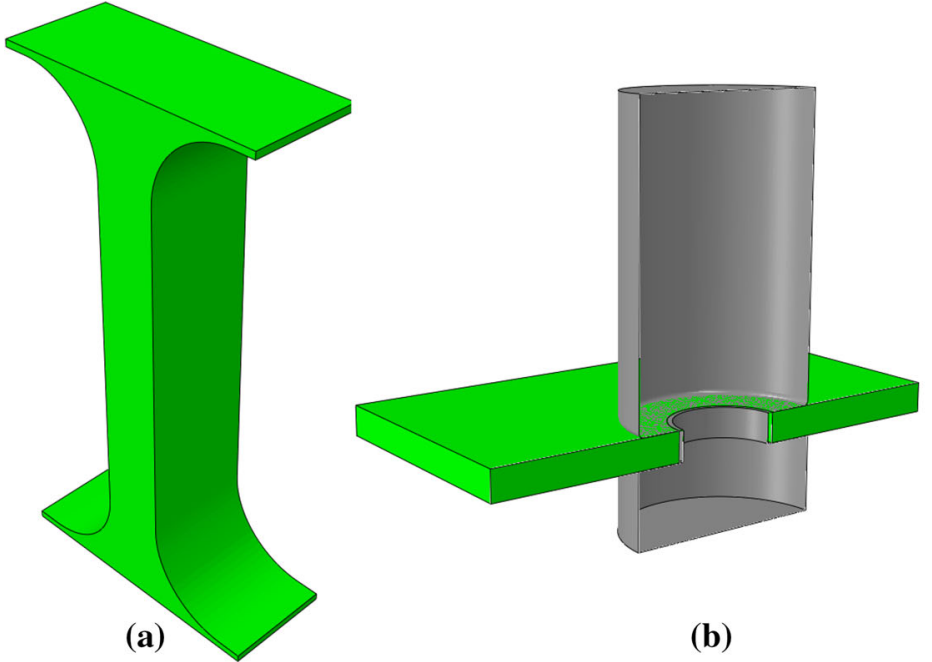

(b)

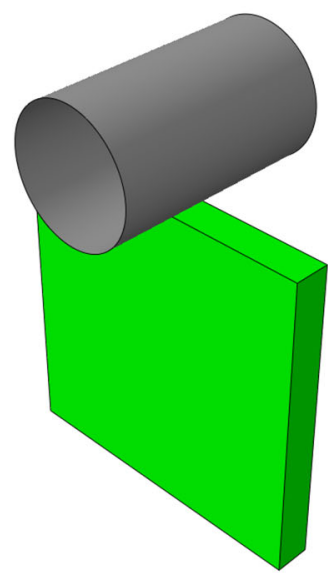

(c) 
Figure 8 Detail of the FE model of the shear punch test: a fillet of the punch; $\mathbf{b}$ element distribution in the foam.
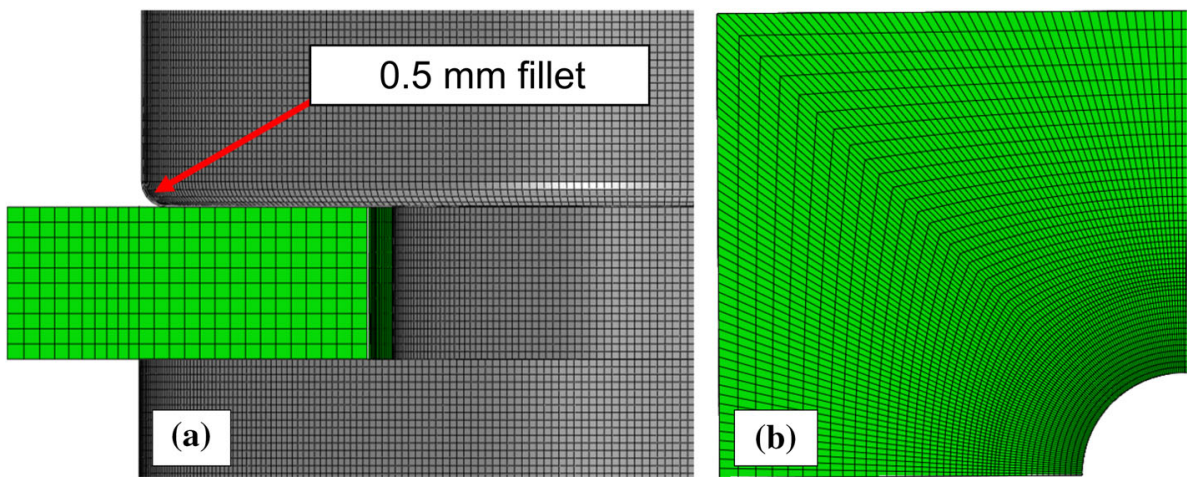
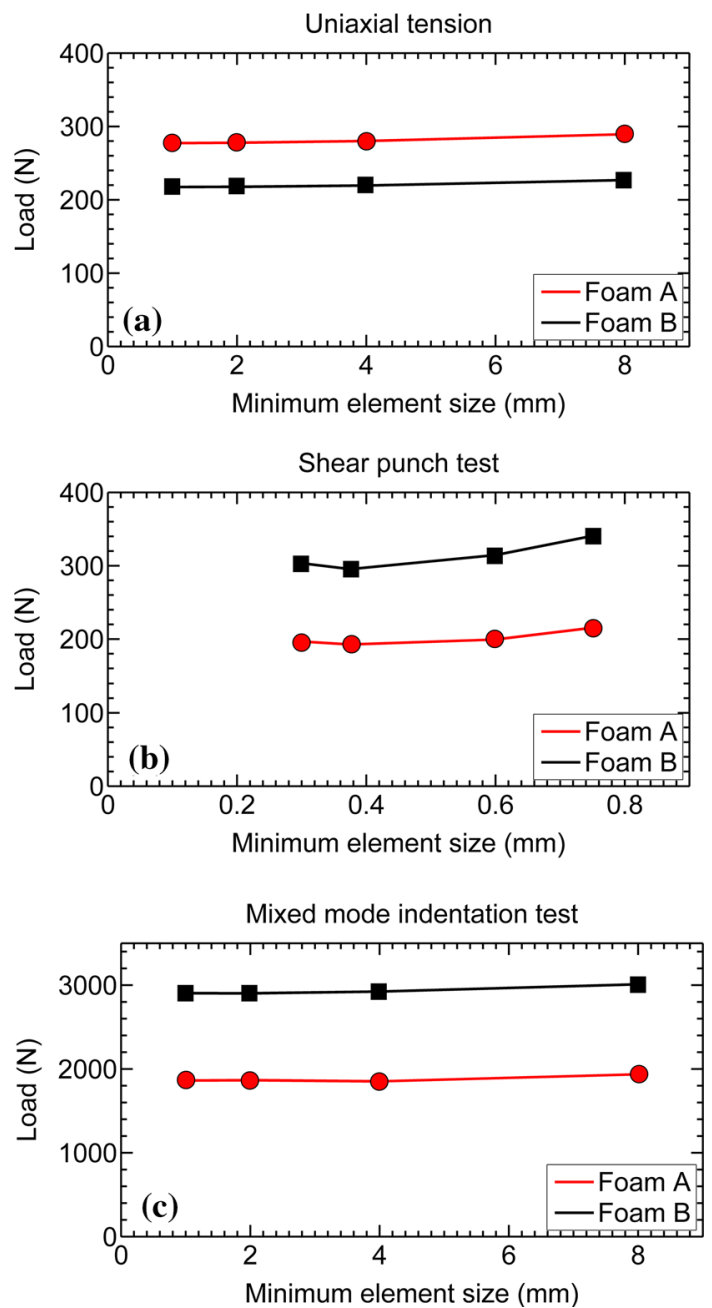

Figure 9 Study of the effect of element size in the FE models of: a uniaxial tensile test; $\mathbf{b}$ shear punch test; $\mathbf{c}$ indentation test. The reaction force was extracted at the same displacement for different meshes when both foams were considered.

computational time excessively, and no remarkable improvement in the numerical predictions was reported.
To introduce failure, a user-defined field (VUSDFLD) subroutine was incorporated into the modelling to delete elements. Deletion was triggered when a maximum strain criterion was satisfied. In particular, it took into account the failure strains in tension and shear in a non-interactive manner. Compressive failure was not considered, since the material should keep densifying under compression and no damage evolution was included. The values for the failure strains were determined from the corresponding experimental tests.

\section{Results and discussion}

\section{Preliminary assessment of the calibration process}

As a first step for assessing the potential applicability of the calibration process which is proposed in this research, data for two PVC foams were used to recreate their yield surfaces. In particular, Deshpande and Fleck [6] gathered information with regards to the mechanical properties of two Divinycell foams, named H100 and H200, respectively, under uniaxial compression, uniaxial tension, shear, hydrostatic compression and hydrostatic tension. The data from the first three tests were used with Eqs. (1)-(4) following the calibration process proposed in "Calibration methodology" section, and the predicted hydrostatic strengths were compared to the values which were measured by Deshpande and Fleck [6]. Figure 10 illustrates a comparison between the resulting yield surfaces for both PVC foams generated with the traditional and the new calibration processes.

It was found that the yield surface recreated by fitting the equations of the constitutive model with 

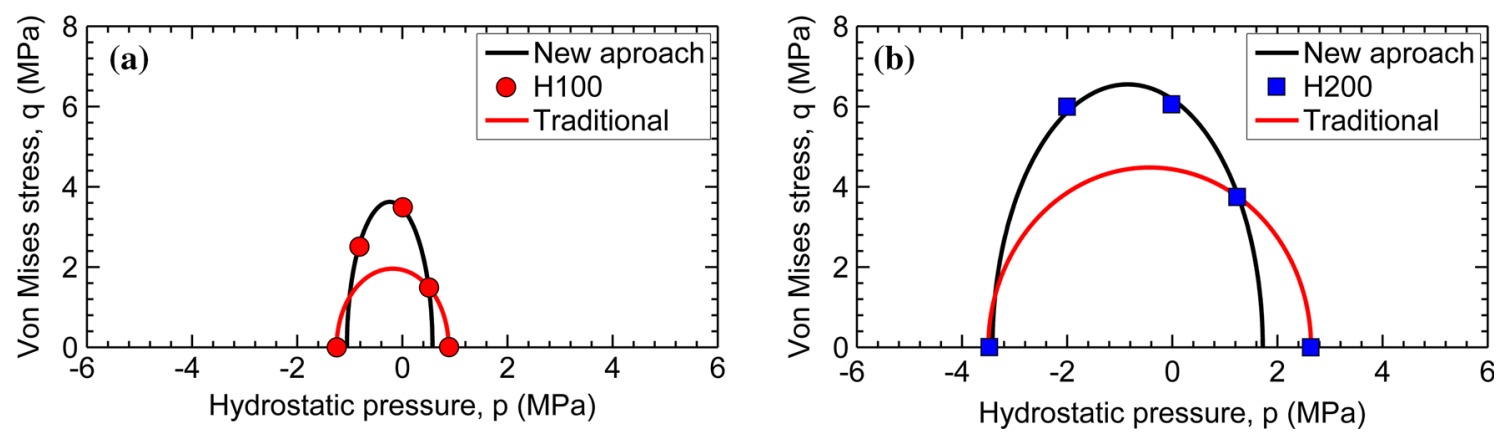

Figure 10 Comparison between the yield surfaces generated with the traditional and the new calibration processes: a Divinycell H100; b Divinycell H200.

the measurements from uniaxial compressive, uniaxial tensile and shear tests predicted the values of hydrostatic tension with good level of accuracy for both foams. A larger discrepancy was observed between the model predictions, using the new calibration process, and experimentally measured hydrostatic compressive strength values. It should be mentioned however, that the conventional calibration process, using uniaxial compressive yield strength, hydrostatic tensile strength and hydrostatic compressive strength as input parameters, significantly underpredicts the yield strength values for shear and tension. Therefore, despite the underestimation of the hydrostatic strength values in compression, the methodology proposed here seems to be a promising alternative for recreating the yield surface of the constitutive model in a simple and systematic way. Indeed, the new calibration process can even give better predictions for stress states more dominated by tension or shear.

\section{Experimental tests for calibrating the material model}

Once the preliminary assessment of the calibration process based on data for other foam systems had been undertaken, the two materials which are considered in this investigation were subjected to uniaxial compression and uniaxial tensile tests at quasistatic rates, as detailed in "Experimental tests" section. Experimental results for tension and compression showed a high level of repeatability. An example of test results for uniaxial compression on foam $A$ is shown in Fig. 11, where excellent repeatability can be observed.

The responses of foams $\mathrm{A}$ and $\mathrm{B}$ under those loading conditions are presented in Fig. 12a and b,

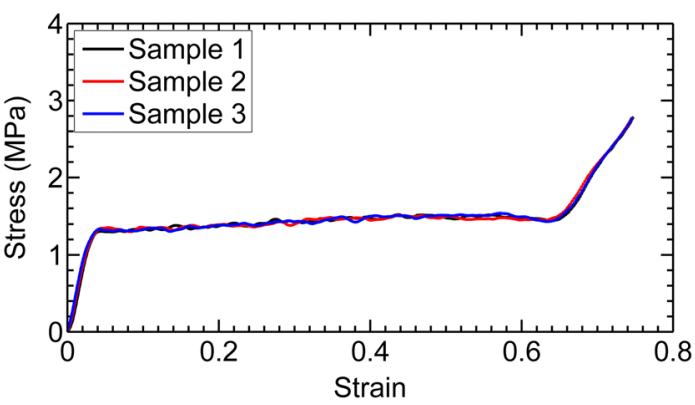

Figure 11 Repeatability of the uniaxial compression test on Foam A.

respectively. The standard error of the mechanical properties which were extracted from these tests is included in Table 1. Whilst the failure mechanisms in tension and compression may be different, the ratio of maximum tensile stress to compressive plateau stress highlights the fact that both foams would present remarkably different failure surfaces in the $p$ $q$ space. This is believed to be the result of the differences in the microstructure (including cell size and wall thickness) of the two foams, which affect the collapse mechanisms of the cells within the material $[1,4,6-11,23]$. The yield strengths were considered as the intersection of the back extrapolation of the linear elastic and nonlinear regions, as explained by Deshpande and Fleck in [6]. As discussed in "Introduction" section, the assumption of elasto-plasticity may not be correct mechanistically, since it is not clear that the foam systems which were considered for this study actually yielded under tensile loading. However, it does provide a way to describe the response phenomenologically. This concept is illustrated for the response of foam A in Fig. 13.

Finally, results for the shear punch tests are illustrated in Fig. 14 for foams A and B. The stress was calculated following the ASTM D732-17 [28]; the load 

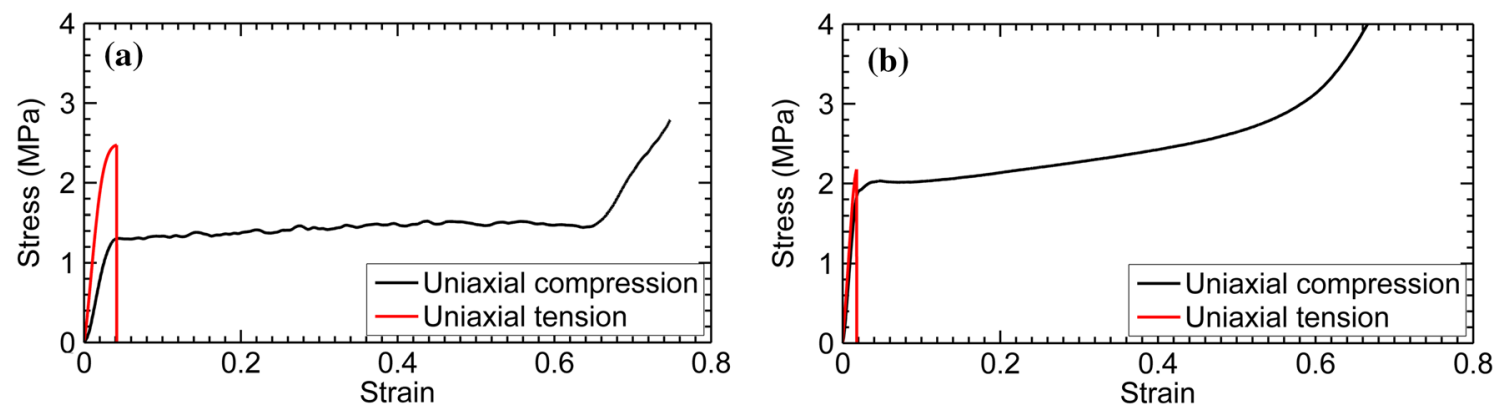

Figure 12 Stress-strain results for uniaxial compression (continuous line) and uniaxial tensile (dotted line) behaviour of: a foam A; b foam $B$

Table 1 Material properties of both foams which are necessary for calibrating the "Crushable Foam" material model in Abaqus

\begin{tabular}{lrr}
\hline Feature & \multicolumn{1}{l}{ Foam A } & \multicolumn{1}{c}{ Foam B } \\
\hline Compressive elastic modulus (MPa) & $39.32 \pm 0.09$ & $123.32 \pm 0.38$ \\
Tensile elastic modulus (MPa) & $92.43 \pm 0.07$ & $143.56 \pm 0.12$ \\
Compressive yield strength (MPa) & $1.30 \pm 0.01$ & $1.90 \pm 0.01$ \\
Tensile strength (MPa) & $2.43 \pm 0.07$ & $2.03 \pm 0.05$ \\
Shear yield strength (MPa) & $0.86 \pm 0.04$ & $1.54 \pm 0.07$ \\
\hline
\end{tabular}

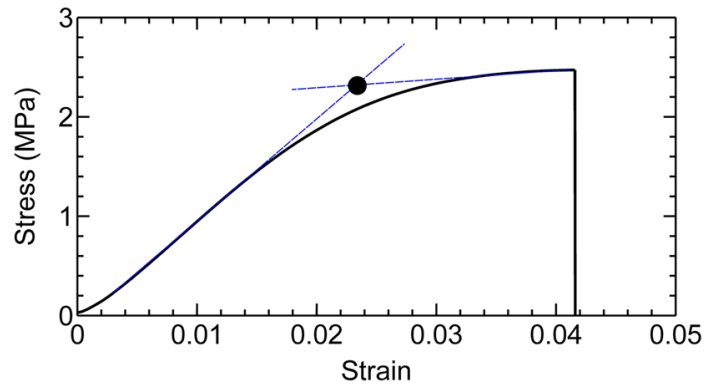

Figure 13 Determination of the tensile yield strength of foam A as the intersection of the back extrapolation of the linear elastic and nonlinear regions.

was divided by the product of the circumference of the punch by the thickness of the sample. As with compression, the shear strength of foam A was lower than that of foam B. Although the deformation of the sample was not visible during the test, studying the

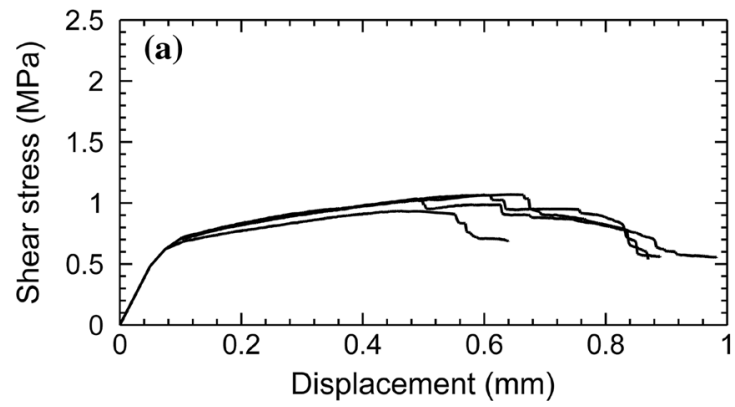

deformed specimens afterwards suggested that the failure was mainly driven by shear but small areas under the punch seemed to have suffered densification as well. Hence, it was assumed that the yielding was caused by shear and then, the subsequent nonlinear region was a combination of shear (dominant stress) and some compression. Section "Calibration of the material model" will refer to this assumption, when the FE model data are discussed. Figure 14 also shows that, while the trends of the observed behaviour were repeatable, some level of variability was seen for this particular loading condition.

\section{Calibration of the material model}

From the proposed experimental tests, mechanical properties were extracted for calibrating the "Crushable Foam" material model and they are introduced

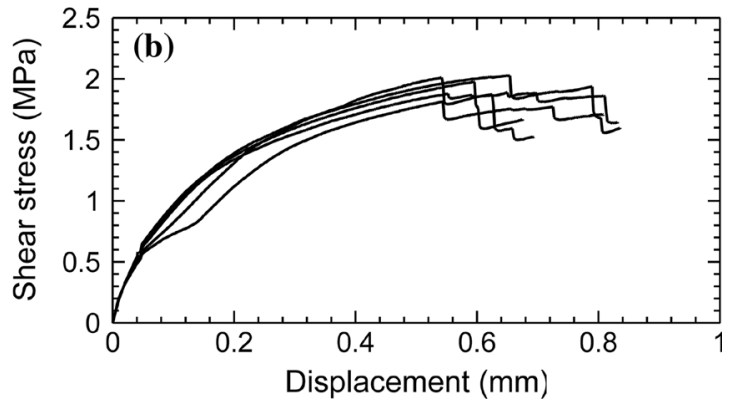

Figure 14 Shear stress-displacement curves obtained from shear punch tests on: a foam A; $\mathbf{b}$ foam B. 
in Table 1, including the corresponding variability due to the repeatability of the tests. The material model was then calibrated by fitting these data in Eqs. (1)-(4), as explained in "Calibration methodology" section, so the yield surface of the foam was recreated. To illustrate this, the resulting yield surfaces of both foams are presented in Fig. 15. From the corresponding fittings, the uniaxial compressive strength to hydrostatic compressive strength ratio $(K)$ and the hydrostatic tensile strength to hydrostatic compressive strength ratio $\left(K_{t}\right)$, which are required by the material model, can be extracted: for foam $\mathrm{A}$, $K$ was equal to 1.94 , whereas $K_{t}$ was 3.63 ; for foam $B$, $\mathrm{K}$ was 2.495 and $K_{t}$ had a value of 1.148 .

Uniaxial tension and shear conditions were simulated as a first step for validating the calibration process. Comparisons between Finite Element models and experimental tests are illustrated in Figs. 16 and 17 for tension, showing a good correlation between numerical results and experiments. With regards to the shear punch tests, Fig. 18 presents comparisons between the stress-displacement curves which were obtained experimentally and the responses predicted by the FE models. The numerical results exhibited a good correlation with those obtained experimentally for both foams. In addition, in "Experimental tests for calibrating the material model" section, it was stated that experimental observations suggested that the yielding was driven by shear and the subsequent nonlinear region was a combination of compressive and shear yielding. Since those assumptions could not be checked during the tests, the stresses were studied in the FE models at the yielding point and at a subsequent point in the nonlinear region. Figure 19 illustrates the stresses for foam A, and it was seen how the yielding was caused by the shear stress and that for higher displacements, small areas under the punch also suffered some compressive yielding. The same observations were made for foam B, validating the assumptions made in "Experimental tests for calibrating the material model" section.

\section{Validation of the calibration process through an indentation test}

The material properties which were generated from the proposed calibration process were used to simulate a more complex indentation test which involved multi-axial loading of the foam under the indenter. Figure 20 represents the load-displacement curve extracted from the test conducted on foam A, along with the predicted FE results. The densification of the foam under the cylindrical roller was visible from early stages of deformation (i.e. at an indenter displacement of around $3 \mathrm{~mm}$ ). The densification continued until two brittle macroscopic cracks developed at around 65 degrees with respect to the horizontal axis at indenter displacement of around $39 \mathrm{~mm}$. The cracks then joined together instantaneously and formed an additional crack parallel to the loading direction, which split the specimen in two parts on the mid-plane. The FE model predicted a fairly accurate load-displacement curve, as shown in Fig. 20 and element deletion started at an indenter displacement of $10.6 \mathrm{~mm}$, developing two final 70.1 degree macroscopic cracks (i.e. about 9\% difference in crack angle with respect to the experimental cracks) at an indenter displacement of $38.7 \mathrm{~mm}$. By analysing the numerical results, it was found that the model removed elements due to shear failure. Figure 21 compares the post-test specimen with the final deformed shape predicted by the FE model, where it is seen how the numerical model was not capable of

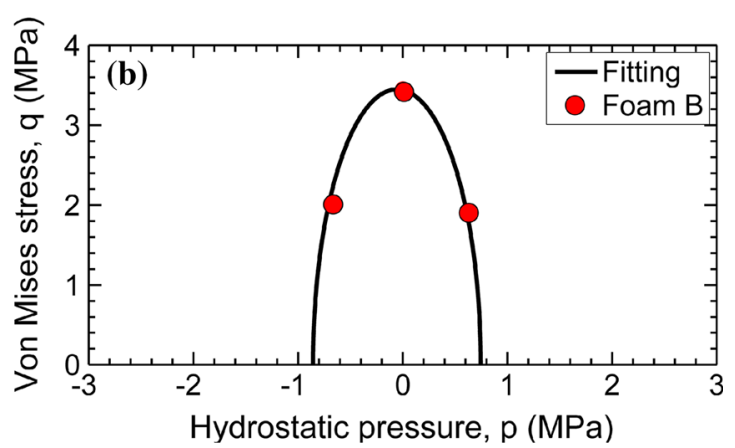

Figure 15 Yield surfaces of both polymeric foams for the "Crushable Foam" model, calibrated by fitting the material strengths into the equations of the constitutive model: $\mathbf{a}$ foam $\mathrm{A} ; \mathbf{b}$ foam $\mathrm{B}$. 

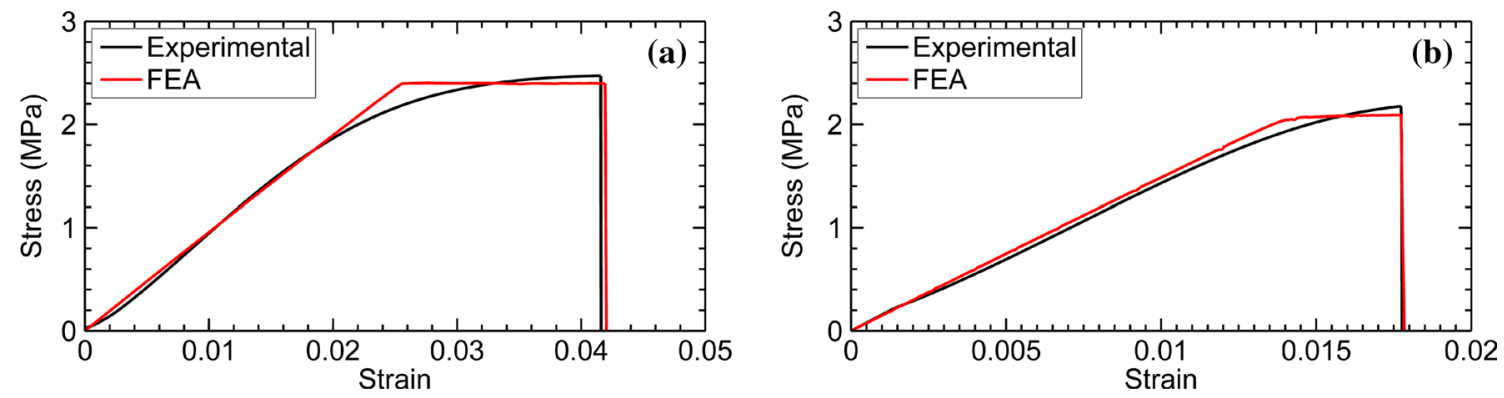

Figure 16 Correlation between experiments and FEA for uniaxial tensile test conducted on a foam A and b foam B: stress-strain response.
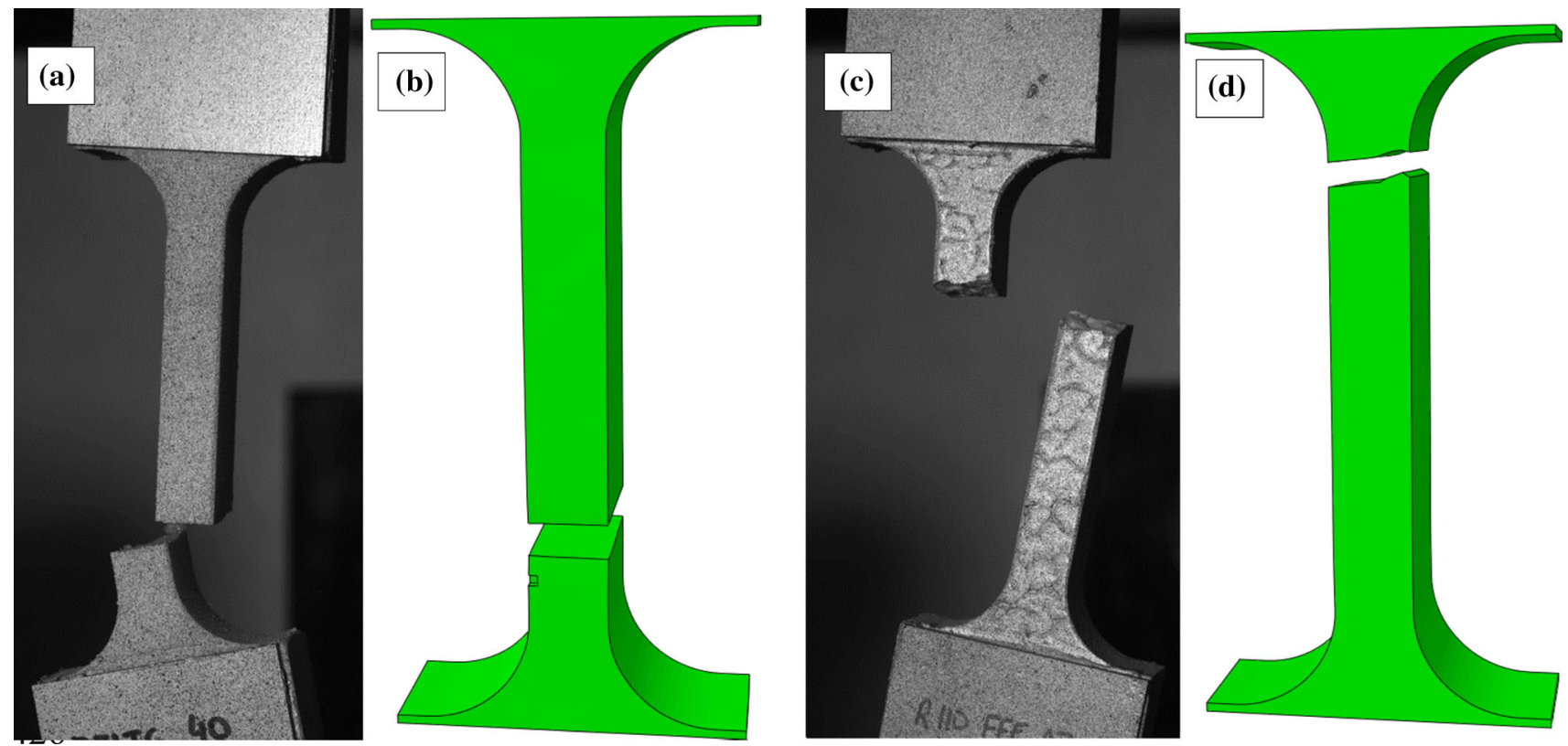

Figure 17 Correlation between experiments and FEA for uniaxial tensile tests (final state): $\mathbf{a}$ foam A (test); $\mathbf{b}$ foam A (FEA); $\mathbf{c}$ foam B (test); $\mathbf{d}$ foam B (FEA).
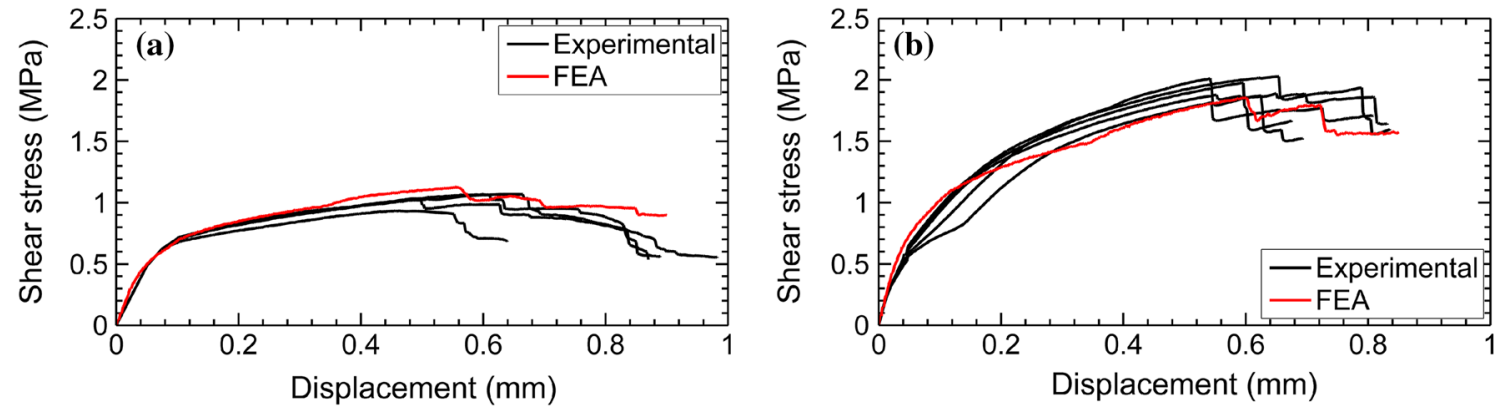

Figure 18 Correlation between experiments and FEA for shear punch test conducted on $\mathbf{a}$ foam A and $\mathbf{b}$ foam $\mathbf{b}$ : stress-displacement response.

reproducing the brittle crack parallel to the loading direction (i.e. the two cracks did not break the sample in two parts instantaneously after they joined together).
Similarly, the correlation between the load-displacement curves of the indentation test and its corresponding FE model for foam $B$ is illustrated in Fig. 22. For this foam, the failure process presented 
Figure 19 Study of the stresses in the FE model of the shear punch test on foam A: a shear stress at the yielding point of the stressdisplacement curve; b compressive stress at the yielding point of the stressdisplacement curve; $c$ shear stress at a displacement of $0.4 \mathrm{~mm}$; $\mathbf{d}$ compressive stress at a displacement of $0.4 \mathrm{~mm}$. Units in MPa. Note that the shear yield strength of foam A was $0.85 \mathrm{MPa}$, while the compressive yield strength was $1.3 \mathrm{MPa}$.
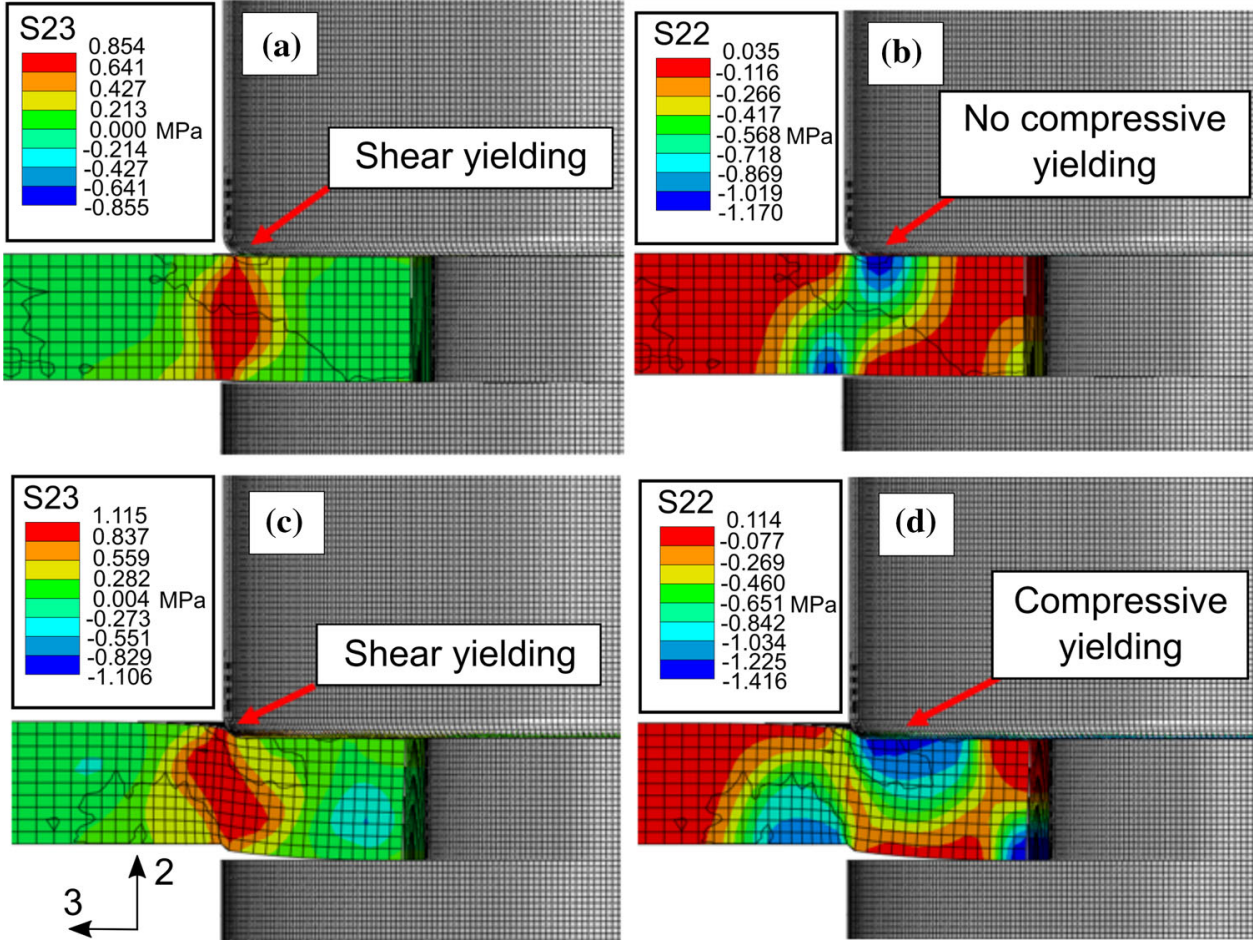

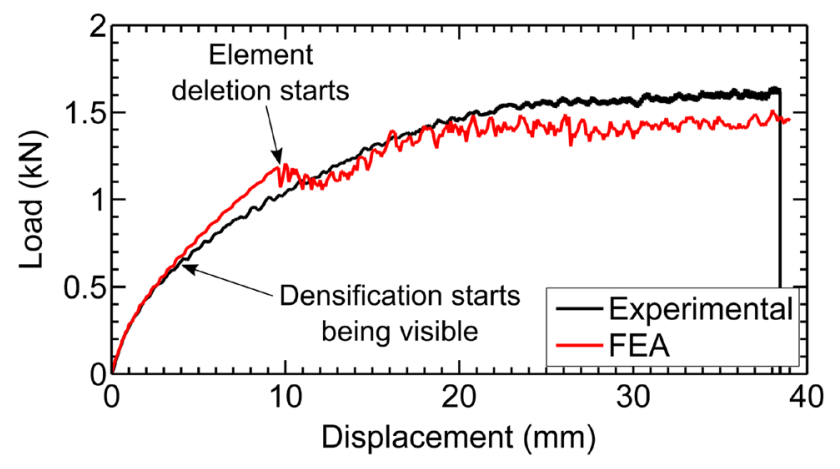

Figure 20 Correlation between experiments and FEA for indentation test conducted on foam A: load-displacement response. different stages; the densification was localised under the indenter from the beginning; then, an initial crack appeared on only one of the sides of the roller at an indenter displacement around $10 \mathrm{~mm}$. As the indentation continued, the first crack propagated towards one of the exterior edges at around 51 degrees with respect to the horizontal axis of the specimen, while a second one initiated on the other side of the sample. Then, the cracks broke the component into different parts as soon as they reached the exterior edges. Finally, the foam suffered buckling and a crack perpendicular to the loading direction grew on top of the clamping area. In Fig. 22, some discrepancies between numerical and experi-
Figure 21 Comparison between the final deformed shapes of the specimens for indentation test conducted on foam A: a real specimen; $\mathbf{b} \mathrm{FE}$ model.
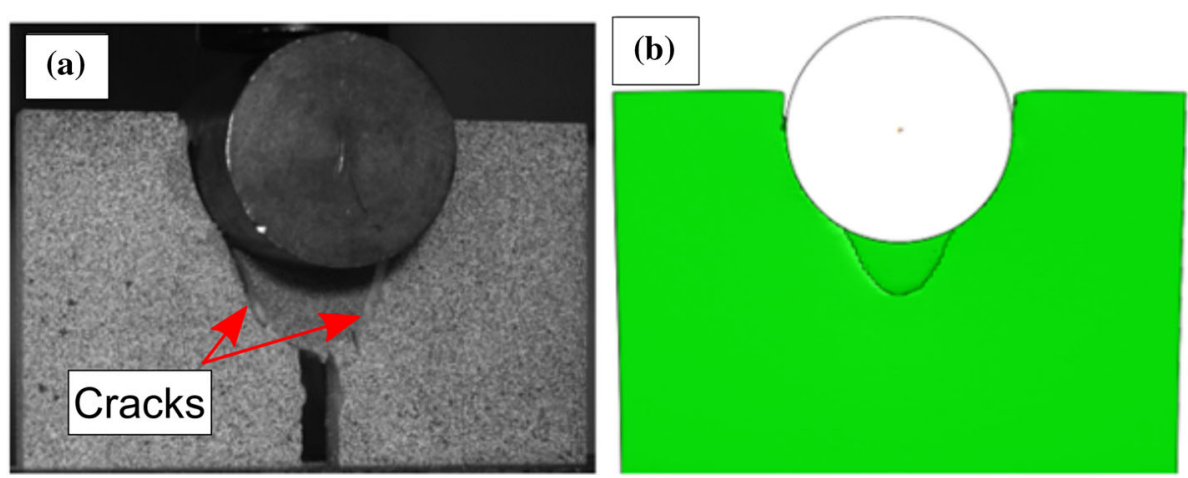


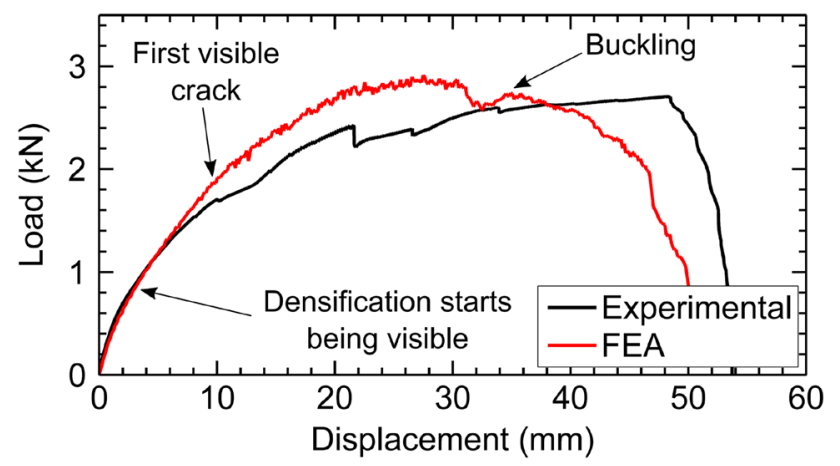

Figure 22 Correlation between experiments and FEA for indentation test conducted on foam B: load-displacement response.

mental results are observed and they are thought to be caused by the micromechanics of the failure process of the foam, which are not captured by the "Crushable Foam" model. In addition, Fig. 23 presents a comparison between the test and the FE model regarding the failure of the foam at different stages. The FE model predicted cracks at 57.5 degrees (i.e. about $13 \%$ difference in the crack angle with respect to the experimental cracks), and according to the model, element deletion was triggered by tensile failure followed by some elements being deleted due to tension and others due to shear failure. This fact can also be a reason for the discrepancies in the loaddisplacement curve, since the element deletion was based on a non-interactive maximum strain criterion. The non-symmetric crack growth in the FE model was caused by the high sensitivity of the subroutine to small differences in strain values, which triggered element deletion earlier on one side, creating stress concentrations which promoted crack propagation. As observed in Fig. 23, however, the final deformed shape correlated well with the tests.

The strain development in the foam was monitored throughout the loading using DIC. The full-field strain measurements were also used to validate the numerical predictions, and Figs. 24 and 25 show the full-field strain contours on the surface of the foam at indenter displacements of $8.70 \mathrm{~mm}$ and $7.50 \mathrm{~mm}$ for foam A and B, respectively. It should be noted that for displacements greater than the values mentioned above, the DIC data were not reliable because of the extensive crushing which occurred under the indenter. At the displacements illustrated in Figs. 24 and 25 , the strain fields were successfully predicted for both foams A and B, except from the area directly under the cylindrical indenter. In that region, the FE models predicted high strain values, whereas experimental results did not show similar values. Once again, this may be caused by the densification of the foam under the indenter, which resulted in the loss of DIC data due to the deterioration of the speckle quality. On the other hand, as stated in "Preliminary assessment of the calibration process" section, the proposed calibration process seems to underestimate the hydrostatic compressive strength. Hence, it could be argued that this difference between the numerical model predictions and the experimental results might be caused by this discrepancy. To check this, the FE models were analysed further. It was observed that the stress state of the material under the indenter was far from hydrostatic compression. On the contrary, for these loading conditions, compression, tension and shear were the dominant stresses, which means that the new calibration process should be predicting more accurate results, as discussed in "Preliminary assessment of the calibration process" section.

In summary, despite some discrepancies between the experimental and numerical results, especially at large deformation, the FE models were able to successfully predict the deformation as well as the failure modes in a complex multi-axial loading scenario. The energy absorbed during the indentation of the foam by a cylindrical indenter is compared in Table 2 for the experimental and numerical results. The energy absorption values were calculated by integrating the areas under the load-displacement curves in Figs. 20 and 22. For foam A, the energy absorption was calculated for the same displacement at which the final failure occurred during the experimental tests. It can be seen how using the calibration process which is proposed in this study provided good estimations of the energy absorbed by both foams under this complex loading condition. In addition, it was found that the difference between experimental and numerical values was consistent for both foams.

\section{Concluding remarks}

Two polymeric foams were used to determine the material characteristics required for the Crushable Foam material model. The methodology which is proposed in this study provides an alternative to a series of complex hydrostatic tests by conducting simple uniaxial compression, uniaxial tensile and 
Figure 23 Comparison between experiment and $\mathrm{FE}$ model regarding the indentation evolution for test conducted on foam B: a first visible crack at indenter displacement of $9.68 \mathrm{~mm}$; b crack growth at indenter displacement of $24.50 \mathrm{~mm}$; c final deformed shape.
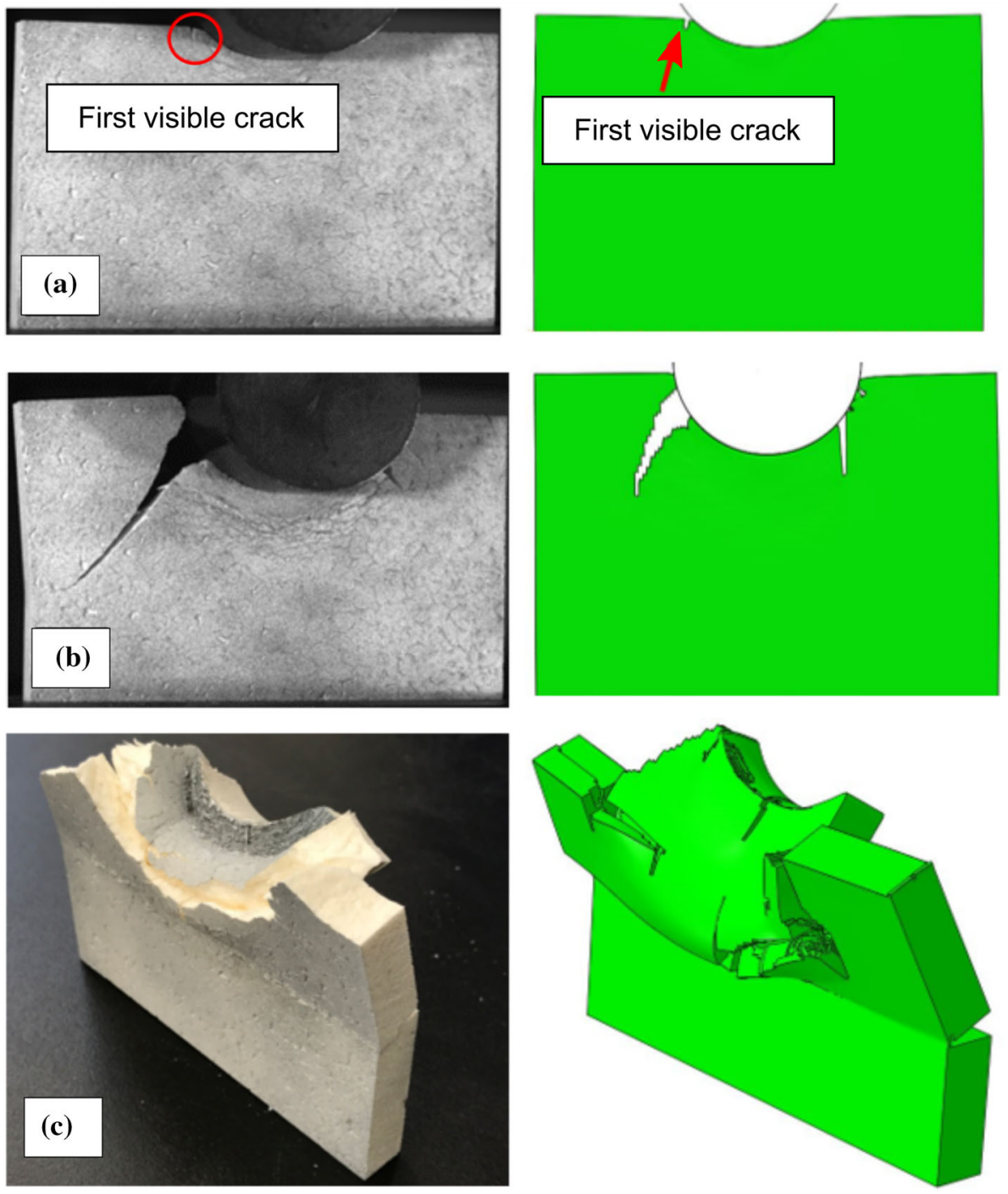

Figure 24 Comparison of compressive strain $\left(\varepsilon_{y y}\right)$ contour between DIC and FEA for foam $\mathrm{A}$ at $8.70 \mathrm{~mm}$ in the load-displacement curve.
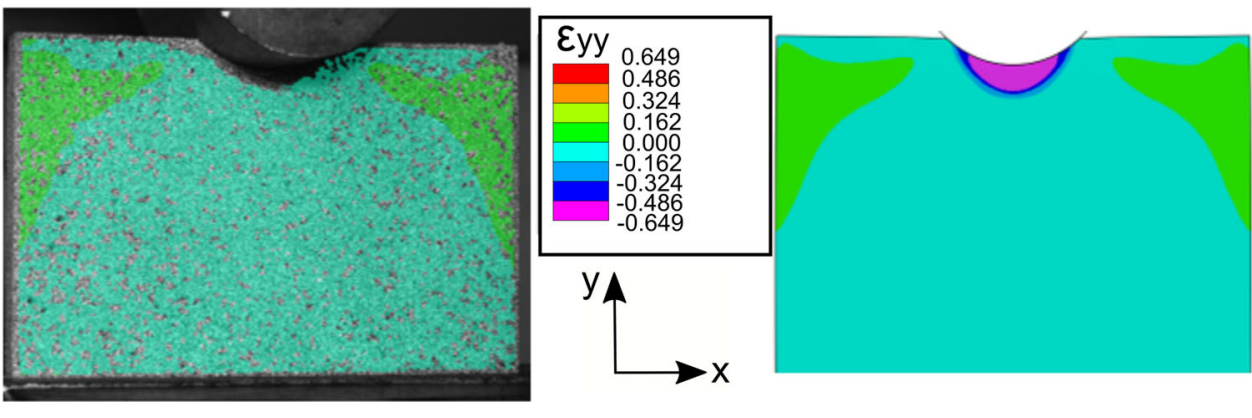

shear punch tests. This new set of experiments provides information regarding the tensile and shear strengths that allow the yield surface of the material model to be determined. The experimental tests were successfully simulated for these loading scenarios. The calibrated material model was then validated by an indentation test which involved a complex multi- axial loading case. DIC was also employed to monitor the strain field under this condition and validate the FE model predictions. Good agreement was observed in terms of load-displacement curves, failure mechanisms, absorbed energy and strain contours. 
Figure 25 Comparison of the compressive strain $\left(\varepsilon_{y y}\right)$ contour between DIC and FEA for foam $B$ at $7.50 \mathrm{~mm}$ in the load-displacement curve.
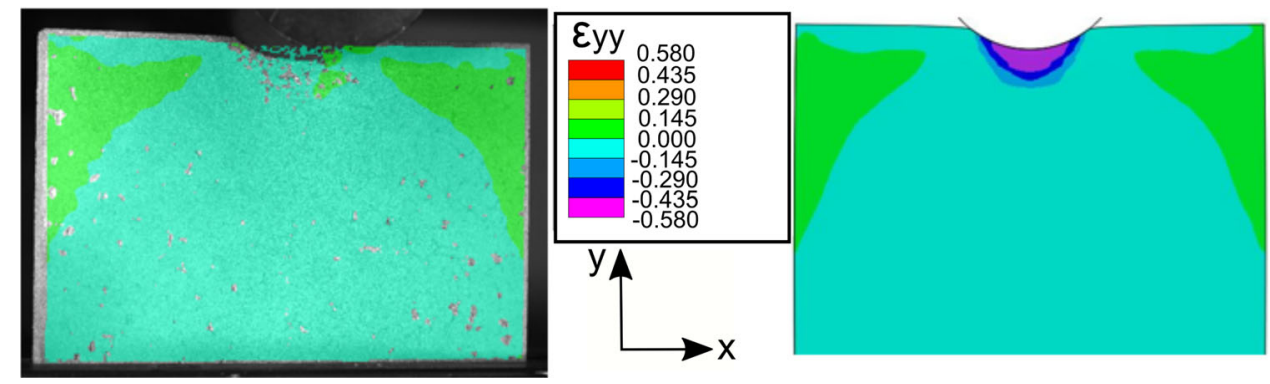

Table 2 Comparison between the energy absorption extracted from the experiments and FE models for the indentation test

\begin{tabular}{lccc}
\hline Foam designation & Energy absorption from tests $(\mathrm{J})$ & Energy absorption from FE $(\mathrm{J})$ & Difference $(\%)$ \\
\hline A & $48.54 \pm 0.16$ & 46.84 & 3.63 \\
B & $115.67 \pm 2.07$ & 111.30 & 3.93 \\
\hline
\end{tabular}

\section{Acknowledgements}

This work has been funded by the Engineering and Physical Sciences Research Council (EPSRC), McLaren Automotive Ltd. and the University of Surrey.

\section{Compliance with ethical standards}

Conflict of interest The content of this publication has been approved by all co-authors and institutions which have been involved in the research, with no conflict of interest, financial or otherwise.

Open Access This article is distributed under the terms of the Creative Commons Attribution 4.0 International License (http://creativecommons.org/ licenses/by/4.0/), which permits unrestricted use, distribution, and reproduction in any medium, provided you give appropriate credit to the original author(s) and the source, provide a link to the Creative Commons license, and indicate if changes were made.

\section{References}

[1] Gibson LJ, Ashby MF (1988) Cellular solids. Pergamon Press, Oxford

[2] Gibson LJ, Ashby MF, Schajer GS, Robertson CI (1982) The mechanics of two-dimensional cellular materials. Proc R Soc Lond A Math Phys Sci 382:25-42

[3] Gibson LJ, Ashby MF (1982) The mechanics of three-dimensional cellular materials. Proc R Soc Lond A Math Phys Sci 382:43-59
[4] Deshpande VS, Fleck NA (2000) Isotropic constitutive models for metallic foams. J Mech Phys Solids 48:1253-1283

[5] Harte AM, Fleck NA, Ashby MF (1999) Fatigue failure of an open cell and closed cell aluminium alloy foam. Acta Metall Mater 47:2511-2524

[6] Deshpande VS, Fleck NA (2001) Multi-axial yield behaviour of polymer foams. Acta Mater 49:1859-1866

[7] Mangipudi KR, Onck PR (2012) Tensile failure of two-dimensional quasi-brittle foams. Int $\mathrm{J}$ Solids Struct 49:2823-2829. https://doi.org/10.1016/j.ijsolstr.2012.03.002

[8] Systemes D (2018) Abaqus 2017 Documentation 2017. h ttp://3www.3ds.com. Accessed 15 Jan 2018

[9] Li QM, Mines RAW, Birch RS (2000) The crush behaviour of Rohacell-51WF structural foam. Int $\mathrm{J}$ Solids Struct 37:6321-6341. https://doi.org/10.1016/S0020-7683(99)002 $77-2$

[10] Li QM, Mines RAW (1999) Strain localization in rigid crushable foam during uniaxial compression

[11] Li QM, Mines RAW (2002) Strain measures for rigid crushable foam in uniaxial compression. Strain 38:132-140. https://doi.org/10.1046/j.1475-1305.2002.00029.x

[12] Mines RAW (2007) Strain rate effects in crushable structural foams. Appl Mech Mater 7-8:231-236. https://doi.org/10. 4028/www.scientific.net/AMM.7-8.231

[13] Arezoo S, Tagarielli VL, Siviour CR, Petrinic N (2013) Compressive deformation of Rohacell foams: Effects of strain rate and temperature. Int J Impact Eng 51:50-57. h ttps://doi.org/10.1016/j.ijimpeng.2012.07.010

[14] Richeton J, Ahzi S, Vecchio KSS, Jiang FCC, Adharapurapu RRR (2006) Influence of temperature and strain rate on the mechanical behavior of three amorphous polymers: 
characterization and modeling of the compressive yield stress. Int J Solids Struct 43:2318-2335. https://doi.org/10. 1016/j.ijsolstr.2005.06.040

[15] Flores-Johnson EA, Li QM, Mines RAW (2008) Degradation of elastic modulus of progressively crushable foams in uniaxial compression. J Cell Plast 44:415-434. https://doi. org/10.1177/0021955x08095113

[16] Arezoo S, Tagarielli VL, Petrinic N, Reed JM (2011) The mechanical response of Rohacell foams at different length scales. J Mater Sci 46:6863-6870. https://doi.org/10.1007/ s10853-011-5649-7

[17] Maji AK, Schreyer HL, Donald S, Zuo Q, Satpathi D (1995) Mechanical properties of polyurethane-foam impact limiters. J Eng Mech 121:528-540. https://doi.org/10.1061/(ASC E)0733-9399(1995)121:4(528)

[18] Triantafillou TC, Zhang J, Gibson LJ, Ashby MF (1989) Failure surfaces for cellular materials under multiaxial loadsI: Modelling. Int J Mech Sci 31:635-663. https://doi.org/10. 1016/s0020-7403(89)80001-3

[19] Siriruk A, Weitsman YJ, Penumadu D (2009) Polymeric foams and sandwich composites: material properties, environmental effects, and shear-lag modeling. Compos Sci Technol 69:814-820. https://doi.org/10.1016/j.compscitech. 2008.02.034

[20] Mostafa A, Shankar K, Morozov EV (2013) Insight into the shear behaviour of composite sandwich panels with foam core. Mater Des 50:92-101. https://doi.org/10.1016/j.matde s.2013.03.016
[21] Yoshihara H, Ataka N, Maruta M (2018) Measurement of the Young's modulus and shear modulus of extruded polystyrene foam by the longitudinal and flexural vibration methods. J Cell Plast 54:199-216. https://doi.org/10.1177/ $0021955 X 16681447$

[22] Gdoutos EE, Daniel IM, Wang K (2001) Multiaxial characterization and modeling of a PVC cellular foam. J Thermoplast Compos Mater 14:365-373

[23] ASTM standard (2013) ASTM C297/C297M standard test method for flatwise tensile strength of sandwich constructions. ASTM Int 04:1-6. https://doi.org/10.1520/c0297

[24] ASTM Standard (2016) ASTM C273/C273M-16 standard test method for shear properties of sandwich core materials. ASTM Int i:1-7. https://doi.org/10.1520/c0273

[25] Chen CP, Lakes RS (1995) Analysis of the structure-property relations of foam materials. Cell Polym 14:186-202

[26] ASTM Standard (2013) ASTM C365/C365M standard test method for flatwise compressive properties of sandwich cores. ASTM Int 2013:1-8. https://doi.org/10.1520/c0365

[27] BS ISO 1926. Rigid cellular plastics-Determination of tensile properties 2009

[28] ASTM Standard (2010) ASTM D732 standard test method for shear strength of plastics by punch tool. ASTM Int, pp 1-4. https://doi.org/10.1520/d0732-17.2

Publisher's Note Springer Nature remains neutral with regard to jurisdictional claims in published maps and institutional affiliations. 